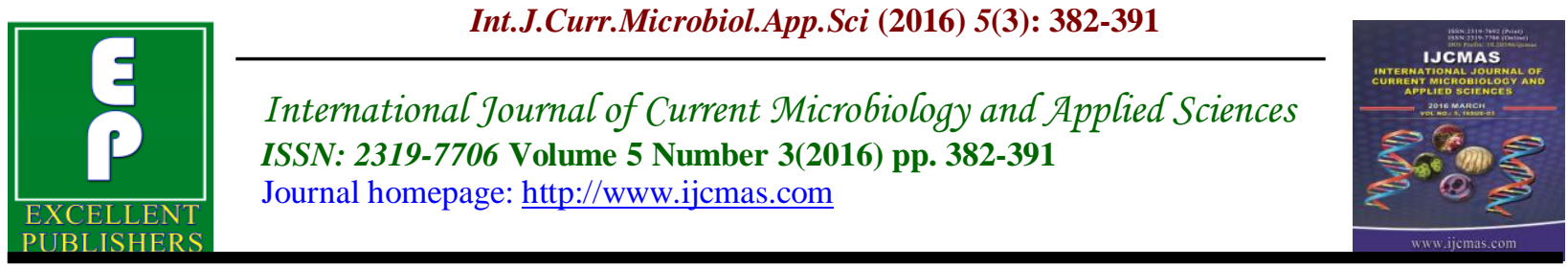

Original Research Article

http://dx.doi.org/10.20546/ijcmas.2016.503.045

\title{
Evaluation of Antioxidative Potential of Field Grown and Tissue Culture Derived Mentha piperita L.Plants
}

\author{
Bidisha Mallick, Suchita Sinha and Debleena Roy* \\ Department of Botany, Lady Brabourne College, P 1/2 Suhrawardy Avenue, \\ Kolkata-700017, India \\ *Corresponding author
}

\begin{abstract}
A B S T R A C T
Keywords

Mentha piperita, Micropropagation, Total phenolic content, Total antioxidant activity, DPPH.

Article Info

Accepted:

16 February 2016

Available Online:

10, March 2016

Mints were aromatic plants belong to the family Lamiaceae. Mentha piperita was the most important herb of this family exploited widely for medicinal purpose making the natural resource threatened. High costs and high demand of this plant for manual labor disallowed large scale propagation with green cuttings. As all species of this genus contained high amount of secondary metabolites, in vitro rapid propagation for production of improved clones was desirable for conservation and commercial exploitation. The aim of the present report was to conserve this medicinal plant for future exploitation through in vitro propagation to evaluate the antioxidative potential of the tissue culture derived clones and to compare it with the in vivo field grown plants so that tissue culture derived plants can be taken in future as an alternative to the naturally grown threatened plants. It was observed that the antioxidant property of the field grown plants were well maintained in the tissue culture derived plant suggesting (total phenols $6.02 \pm 0.03 \mathrm{mg}$ GAE/g, rosmarinic acid $7.28 \pm 0.28 \mathrm{mg} / \mathrm{g}$, total flavonoid content $49.290 \pm 0.48 \mathrm{mg} \mathrm{QE} / \mathrm{g}$ ) in vitro regeneration as an alternative for sustainable use of this medicinally important threatened plant.
\end{abstract}

\section{Introduction}

Epidemiological and experimental studies reveal a negative correlation between the consumption of diets rich in fruits and vegetables and the risks for chronic angiogenic diseases, such as cardiovascular diseases, arthritis, chronic inflammation and cancer (Miller, et al., 2000). Radicals of oxygen (super oxide anion, hydroxyl radical and peroxy radicals), reactive non radical oxygen species such as hydrogen peroxide and singlet oxygen, as well as carbon, nitrogen and sulphur radicals comprise the variety of reactive molecules that can cause damage to cell. Phenolic compounds safely interact with free radicals and terminate the chain reaction before the vital molecules are damaged. The polyphenols inhibit low density lipoprotein (LDL) oxidation in vivo, which is considered a risk factor in atherosclerosis. The antioxidative activity of phenolics is mainly due to their redox properties, which allow them to act as 
reducing agents, hydrogen donors and singlet oxygen quenchers. In addition they have a metal chelation potential (Rice Evans et al., 1995). The phenolic compounds are of increasing interest in the food and drug industry because they retard oxidative degradation of lipids and thereby improve the quality and nutritional value of food (Kahkonen et al., 1999).

The ethno botanical reports offer information about the medicinal properties of the herbs which include details of their antidiabetic, antihistaminic, anticarcinogenic and antibacterial activities. Plant phenolics are commonly found in both edible and nonedible plants and have been reported to have multiple biological effects; including antioxidant activity. So the attention has been devoted to herbs, which though unexploited in most cases, possess a tremendous potential to help people overcome the deadly diseases of the modern society. In rural areas utilization of wild populations of different common medicinal plants as crude drugs is a regular practice among the poor people for treatment against the life threatening diseases. In addition the pharmaceutical companies also make use of wild populations of different medicinal plants for their own interest. All these have created an increased demand of many medicinal plants including Mentha.

Mentha, the culinary herb of the family lamiaceae has been grown and used for thousands of years all over the globe to flavor foods. This herb also has been identified as a source of various phytochemicals, including polyphenols which are highly effective antioxidants and less toxic than the well-known synthetic antioxidants as BHA and BHT (Sreenivasan et al., 2007). Plant extracts, due to their presence of secondary metabolites possess similar or even higher antioxidant activity; can be natural alternatives to synthetic antioxidants, so they are strongly of interest in the food and drug industry (LeFloch et al., 1998). As all species of the genus contain high amounts of secondary metabolites, this genus is getting over exploited by the food and drug industries making the natural resource threatened. In vitro rapid propagation for the production of improved clones is desirable for rapid conservation and commercial exploitation of this economically important threatened plant (Roy et al., 2012). To preserve these medicinal plants from future extinction, cultivation is necessary. Extraction of secondary metabolites (which is responsible for its medicinal properties) from naturally grown whole plants on a commercial basis involves large scale crop cultivation. But with the increase in world population less availability of cultivable land, environmental and geopolitical instabilities make the cultivation procedure increasingly difficult. So there is an increase in concern throughout the world about the uncontrolled exploitation and depletion of earth's natural resources. Hence the application of plant tissue culture has gained major industrial importance in three main areas: 1. In breeding and genetics - a way to conservation (Julia and Claudia 2012). 2. As model systems for plant biochemistry and pathology- ways to produce disease free crops. 3. Production of secondary metabolites - for exploitation in food, drug and pharmaceutical industries (Tisserat and Vaughn 2008). So the application of the tissue culture technique will be very useful in order to conserve and future augmentation of the metabolites present in these very useful medicinal plants.

The aim of the present report is to conserve this medicinal plant for future exploitation through in vitro propagation and to evaluate the antioxidative potential of the tissue culture derived clones and to compare it with the in vivo field grown plants so that 
tissue culture derived plants can be taken in future as an alternative source of food and drug in comparison with the naturally grown threatened plants.

\section{Materials and Methods}

\section{Collection of Plant Material}

The plant selected for this study Mentha piperita L. was collected from NBPGR, New Delhi bearing strain no IC: 54537. Field grown plants were maintained in the medicinal garden of Lady Brabourne College. The antioxidant potential of the field grown plants in 4 seasons (summer, monsoon, autumn and winter) were taken into account and an average was calculated and the average annual productivity was compared with the in vitro regenerates.

\section{In Vitro Culture}

Apical and nodal portions with axillary buds of 2-3 cm length from field grown plants were taken as explants. Media used for in vitro culture was Murashige and Skoog (MS) modified basal medium supplemented with $3 \%(\mathrm{w} / \mathrm{v})$ sucrose, $0.05 \mathrm{mg} / \mathrm{L}(\mathrm{w} / \mathrm{v})$ ascorbic acid, $0.1 \mathrm{mg} / \mathrm{L}(\mathrm{w} / \mathrm{v})$ glutamine, $0.25 \% \quad(\mathrm{w} / \mathrm{v})$ Gelrite ${ }^{\circledR}$ and different combinations of growth regulators. Different growth regulators, NAA: $\alpha$ naphthaleneacetic acid and BAP: 6benzylaminopurine was added in different combinations and concentrations in MS basal media. The culture vessels containing media were autoclaved at $121^{\circ} \mathrm{C}$ for $15 \mathrm{~min}$. Explants were inoculated in sterile nutrient media contained in culture vessel under aseptic condition in a laminar air flow chamber. All the cultures were maintained in a culture room at $24 \pm 1{ }^{\circ} \mathrm{C}$ in a light intensity of $48 \mu \mathrm{mol} \mathrm{m} \mathrm{m}^{-2} \mathrm{~s}^{-1}$ photosynthetic photon fluxes. Cultures were maintained by sub-culturing the material after every 4 weeks under aseptic condition. Shoots collected from plants regenerated in vitro in a medium with best response were considered as control. Antioxidative potentials were analyzed from control tissues and compared with in vivo plants.

Preparation of the plant extract: The fresh leaves $(5 \mathrm{~g})$ was crushed with $50 \mathrm{ml} 80 \%$ methanol in a homogenizer (REMI) and filtered. The content was decanted through a filter paper and the residue was re-extracted again with $80 \%$ methanol. The extracts were lyophilized (Hahntec Lyophilizer) till free of solvents and crude extract was prepared. A comparative study was done using ethanol as solvent.

Estimation of phenolics: The amount of total phenolics in extracts was determined with the Folin ciocalteau reagent. Gallic acid was used as a standard and the total phenolics were expressed as $\mathrm{mg} / \mathrm{g}$ gallic acid equivalents (GAE). $1 \mathrm{mg} / \mathrm{ml}$ of plant extract were prepared in methanol and $0.5 \mathrm{ml}$ of each sample was introduced into test tubes. It is mixed with $2.5 \mathrm{ml}$ of 10 fold dilute Folin ciocalteau reagent and $2 \mathrm{ml}$ of $7.5 \%$ sodium carbonate. The reaction mixture is allowed to stand for 30 minutes at room temperature and the absorbance was read at $760 \mathrm{~nm}$ in UV-Vis spectrophotometer. The concentration was calculated using gallic acid as the standard and the results were expressed as mg gallic acid equivalents/g of extract. The standard curve was drawn using gallic acid as standard. The total phenolic content was determined as GAE (gallic acid equivalent) using an equation $\left(\mathrm{y}=\mathrm{a}^{*} \mathrm{x}, \mathrm{a}=\right.$ $9.909+/-0.3133)$ from the calibration curve of gallic acid standard solution (covering the concentration range between $20 \mu \mathrm{g}$ to $100 \mu \mathrm{g})$.

High performance liquid chromatography (HPLC) analysis of rosmarinic acid for 
quantification-High Performance Liquid Chromatography (HPLC) (Shimadzu, SPD10A UV-Vis detector, LC-10 AD Liquid chromatography) separation was achieved by using a C18 column, $(150 \times 4.6 \mathrm{~mm}$, Hypersil) with a particle size $5.0 \mu \mathrm{m}$ and the temperature was set at $30^{\circ} \mathrm{C}$. The flow rate was $0.5 \mathrm{ml} / \mathrm{min}$. The mobile phase for chromatographic analysis was with water: acetonitrile $(83: 17 \mathrm{v} / \mathrm{v})$. Ultraviolet detection was set at $330 \mathrm{~nm}$.

Estimation of flavonoids: Total flavonoid content was measured by the aluminium chloride colorimetric assay, Ebrahimzadeh et al., 2008. In this method quercetin was used as standard and flavonoid contents were measured as quercetin equivalent from the standard curve $(\mathrm{y}=\mathrm{a} * \mathrm{x}, \mathrm{a}=0.001339+/-$ $0.3133) .1 \mathrm{ml}$ of extract $(500 \mu \mathrm{g} / \mathrm{ml})$ was added to a $10 \mathrm{ml}$ volumetric flask containing $4 \mathrm{ml}$ of distilled water. $0.3 \mathrm{ml} 5 \% \mathrm{NaNO}_{2}$ was added. After 5min, $0.3 \mathrm{ml} 10 \% \quad \mathrm{AlCl}_{3}$ was added. At $6^{\text {th }}$ min, $2 \mathrm{ml} 1 \mathrm{M} \mathrm{NaOH}$ was added and the total volume was made up to $10 \mathrm{ml}$ with water. The solution was mixed well and the absorbance was measured against prepared reagent blank at $510 \mathrm{~nm}$ by UV-Vis spectrophotometer.

Total antioxidant activity: The total antioxidative activity was measured by using the method described by Prieto et al., (1999). Plant extracts were dissolved in methanol to obtain a concentration of $500 \mu \mathrm{g} / \mathrm{ml} .0 .3 \mathrm{ml}$ of extract was placed in a test tube; $3 \mathrm{ml}$ of reagent solution $(0.6 \mathrm{M}$ $\mathrm{H}_{2} \mathrm{SO}_{4}+28 \mathrm{mM}$ Sodium phosphate+ $4 \mathrm{mM}$ Ammonium molybdate) was added. The reaction mixture was incubated at $95^{\circ} \mathrm{C}$ for 90 minutes. The mixture was cooled to room temperature; the absorbance of each solution was measured by using Systronics UV-Vis spectrophotometer at $695 \mathrm{~nm}$ against blank. The experiment was performed in triplicate. A calibration curve was constructed, using
Ascorbic acid $(100-500 \mu \mathrm{g} / \mathrm{ml})$ as standard and total antioxidant activity of extract $(\mu \mathrm{g} / \mathrm{ml})$ expressed as ascorbic acid equivalents.

\section{Free Radical Scavenging Activity}

The antioxidant activity of the extracts was assessed by their ability to scavenge 2-2 diphenyl-1picryl hydrazyl stable radicals (DPPH) by using the methods of Shimada $e t$ al., 1992. $1 \mathrm{ml}$ of methanolic extract and 5 $\mathrm{ml}$ of freshly prepared $0.1 \mathrm{mM} \mathrm{DPPH}$ methanolic solution were thoroughly mixed and kept in the dark for 60 minutes. The absorbance of the reaction mixture at 517 $\mathrm{nm}$ was measured by spectrophotometer. The blank set was prepared by replacing the extract with methanol $(1 \mathrm{ml})$. The percentage of free radical scavenging activity was calculated as follows:

Free radical scavenging $(\%)=100$ - (1$\mathrm{A}_{\text {sample }} / \mathrm{A}_{\text {blank}}$ ),

Where A blank is the absorbance of the control and A sample is the absorbance of the extract or ascorbic acid. All the tests were run in triplicate and averaged.

Statistical analysis: Data were analyzed statistically following one way Anova assay to determine the least significant difference. Three replications of each set of experiment were taken for study and an average was calculated.

\section{Results and Discussion}

Apical buds were most suitable explant sources for multiplication of peppermint. The bud break was observed mostly between 8-11 days after culture in all cases. All the cultures were maintained up to fifteen weeks. For peppermint various combinations of different cytokinins on 
shoot bud multiplication were used with one auxin NAA $(0.25 \mathrm{mg} / \mathrm{L})$. The media containing $0.25 \mathrm{mg} / \mathrm{L} \mathrm{NAA}$ and $2.5 \mathrm{mg} / \mathrm{L}$ BAP produced highest number of shoot buds (58.0 \pm 0.82 shoot buds per explant) (Fig. 1, 2, 3). BAP showed the highest potentiality for shoot bud multiplication than the other two cytokinins tested. Root formation started after fifteen days of culture. Presence of auxin only gave a better response in root production. After complete regeneration they were transferred to the pre acclimation chamber (PAC). The plants were maintained there up to 3 weeks. The upper half of the PAC was removed after 3 weeks and kept in outer environment. It was seen that plants survived with a good growth (Fig 4). Somatic chromosome analysis of regenerated plants showed chromosome number stability with $2 \mathrm{n}=36$ in $M$. piperita. The eight week old plants are taken for further tests.

The present investigation on multiplication of Mentha piperita L. revealed that the cytokinin BAP is more efficient in shoot bud multiplication than other cytokinins. Effectiveness of BAP in shoot bud multiplication was also earlier reported in Mentha by different authors (Phatak and Heble 2001, Ghanti et al., 2004, Sunandakumaril et al., 2004) and in other plant species (Dode et al., 2003).The requirement of such different levels of cytokinins may be correlated with the difference in its endogenous level in different populations and species studied, that may also be linked to its habitats. Also, the genotypic differences might have been responsible for the difference in responses in different populations and species (Lahiri 2010). Chromosome analysis revealed chromosome number stability in the regenerates. This may indicate the efficacy of BAP and the culture conditions in maintaining the genome stability of the regenerates. Such chromosome number stability in the regenerates has also been observed using BAP as the only cytokinin in culture medium (Lahiri 2010).

The methanolic extracts of various plant samples of Mentha species were analyzed for total phenol and flavonoids (Table 1). The results showed that among the two solvents used methanol proves to be more efficient than the other (Data not shown). The amount of total phenol varies in the four seasons for field grown plants with an average of $5.82 \pm 0.03 \mathrm{mg} \mathrm{GAE} / \mathrm{g}$ of methanolic extracts where tissue culture derived plants showed continuous and constant production of total phenolics $(6.24 \pm 0.03 \mathrm{mg}$ GAE$/ \mathrm{g})$ which is $7 \%$ more than the field grown plants. Rosmarinic acid content also showed slight increased (4\%) in tissue culture derived plants. In case of total flavonoid content, it also varies through the season with an average production of $48.542 \pm 0.24 \mathrm{mg} \mathrm{QE} / \mathrm{g}$ of the extracts where tissue culture derived plants showed similar and continuous production of total flavonoid content. Tissue culture derived plant had a higher content of phenol as compared to the field grown plants. The reports of Akashdeep et al., 2014 are in accordance with our results.

Seasonal variation of phenol and rosmarinic content had been reported earlier. The total phenolic content of Mentha varies in each season. In summer the plant growth was average. During monsoon a vigorous growth was observed with a slight decrease in total phenol content than in summer. During winter the growth rate was declined. Similar results were also observed by Ravn et al., (1994) in other plant species, where seasonal variation of total phenolic content including rosmarinic acid was observed. The influence of environmental conditions on quantity of active constituents in various plants has been 
reported. It was observed that phenolic acid, flavonol and anthocyanin contents and antioxidant activity in fruit juice of Fragaria ananassa were considerably influenced by day and night growing temperature combinations (Zheng and Wang 2001). It was observed by many researchers that the physiological and biochemical changes are synergistic effects of different biotic and abiotic parameters.

In most of the plants exposure to high and low temperature than the optimum was regarded to be the main cause (Dixon 1995). It is difficult to determine which environmental factor is mainly responsible for the variations. In laboratory experiments factors can be set and regulated exactly (Siatka and Kasparova 2010). So by providing tissue culture approaches, a shoot based clonal line was tested here for experimental purpose and it was observed that a continuous stable production of total phenolics, total flavonoids and rosmarinic acid content was synthesized in shoot based clonal lines.

\section{Total Antioxidant Capacity}

Total antioxidant capacity of the methanolic extracts was determined from regression equation of calibration curve $(\mathrm{y}=\mathrm{ax}$, where $\mathrm{a}=0.001845)$ and expressed as ascorbic acid equivalents. The total antioxidant capacity of extracts of field grown Mentha plants was found to be $16.385 \pm 0.24 \mu \mathrm{g} / \mathrm{ml}$ (expressed as ascorbic acid equivalents) at a concentration of $50 \mu \mathrm{g} / \mathrm{ml}$, that of tissue cultured plants was $20.833 \pm 0.36 \mu \mathrm{g} / \mathrm{ml}$ (expressed as ascorbic acid equivalents) at the same concentration.

The phosphomolybdenum method was based on the reduction of Mo (VI) to Mo (V) by the antioxidant compound and the formation of a green phosphate/Mo(V) complex with a maximum absorption at 695 $\mathrm{nm}$. This assay is used to quantify vitamin $\mathrm{E}$ in seeds (Raghavendra et al., 2010). The extract of Mentha plants from field showed a total antioxidant capacity of $29.722 \mu \mathrm{g} / \mathrm{ml}$ calculated as ascorbic acid equivalents. The tissue culture derived sample extract however showed a greater total antioxidant capacity which was $39.722 \mu \mathrm{g} / \mathrm{ml}$ (Fig 5).

The results were not significantly different from each other $(\mathrm{p}<0.05)$.Our results are similar to the results obtained from the extracts of Phyllanthus niruri, where the in vitro plants had higher TAC value than the samples obtained from the market (Gami and Kothari 2011).

The results indicate a concentration dependent total antioxidant capacity. It means that the methanol extracts of Mentha will have to contain as much quantity of antioxidant compounds as equivalents of ascorbic acid to effectively reduce the oxidant in the reaction matrix. Antioxidant capacity of ascorbic acid has been used as a reference standard from which plant extracts with potential antioxidant activity are compared (Aliyu et al., 2012).

\section{DPPH Radical Scavenging Activity}

The DPPH radical scavenging activities of the extracts were given in Figure 6.The activity increased by increasing the concentration of the sample extract. This assay has been largely used as a quick, reliable and reproducible parameter to search for the in vitro antioxidant activity of pure compounds as well as plant extracts. This assay is based on the ability of 1, 1diphenylpicryl hydrazyl (DPPH), a stable free radical, to decolorize in the presence of antioxidants. The DPPH radical contains an odd electron, which is responsible for the absorbance at $515 \mathrm{~nm}$ and also for a visible deep purple colour. 
Table.1 Determination of total phenol, rosmarinic acid and total flavonoid

\begin{tabular}{|l|c|c|c|}
\hline \multicolumn{1}{|c|}{ Plant sample } & $\begin{array}{c}\text { Total phenol } \\
(\mathrm{mg} \mathrm{GAE} / \mathrm{g}) *\end{array}$ & $\begin{array}{c}\text { Rosmarinic acid } \\
(\mathrm{mg} / \mathrm{g}) * \mathrm{~ns}\end{array}$ & $\begin{array}{c}\text { Total flavonoid content } \\
(\mathrm{mg} \mathrm{QE} / \mathrm{g}) * \mathrm{~ns}\end{array}$ \\
\hline Field grown plants & $5.82 \pm 0.03$ & $7.00 \pm 0.08$ & $48.542 \pm 0.24$ \\
\hline Tissue culture derived plants & $6.24 \pm 0.03$ & $7.28 \pm 0.28$ & $49.290 \pm 0.48$ \\
\hline
\end{tabular}

*Data expressed as Mean \pm S.E. from 3 replicates; $\mathrm{P} \leq 0.0001$. $\mathrm{ns}=$ nonsignificant. Means were compared by one way Anova and on the basis of analysis it can be said that $\mathrm{F}$ values are higher than critical $\mathrm{F}$ values at $0.01 \%$ level of significance. The data indicates significant differences between phenolic content

Fig.1 Bud Break, Fig.2 Shoot Bud Multiplication, Fig.3 Direct Regeneration, Fig.4 Hardening

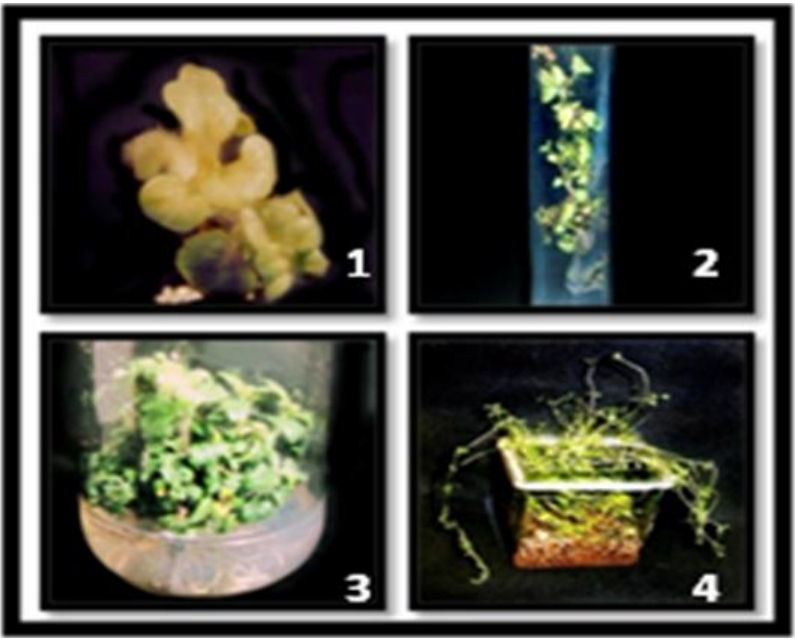

Fig.5 Total Antioxidant Capacity of Field Grown (MM) and Tissue Cultured (MV) Mentha piperita L. Plants Expressed as $\mu \mathrm{g} / \mathrm{ml}$ of Ascorbic Acid

(Values are Expressed as Mean + SEM, $n=3$ )

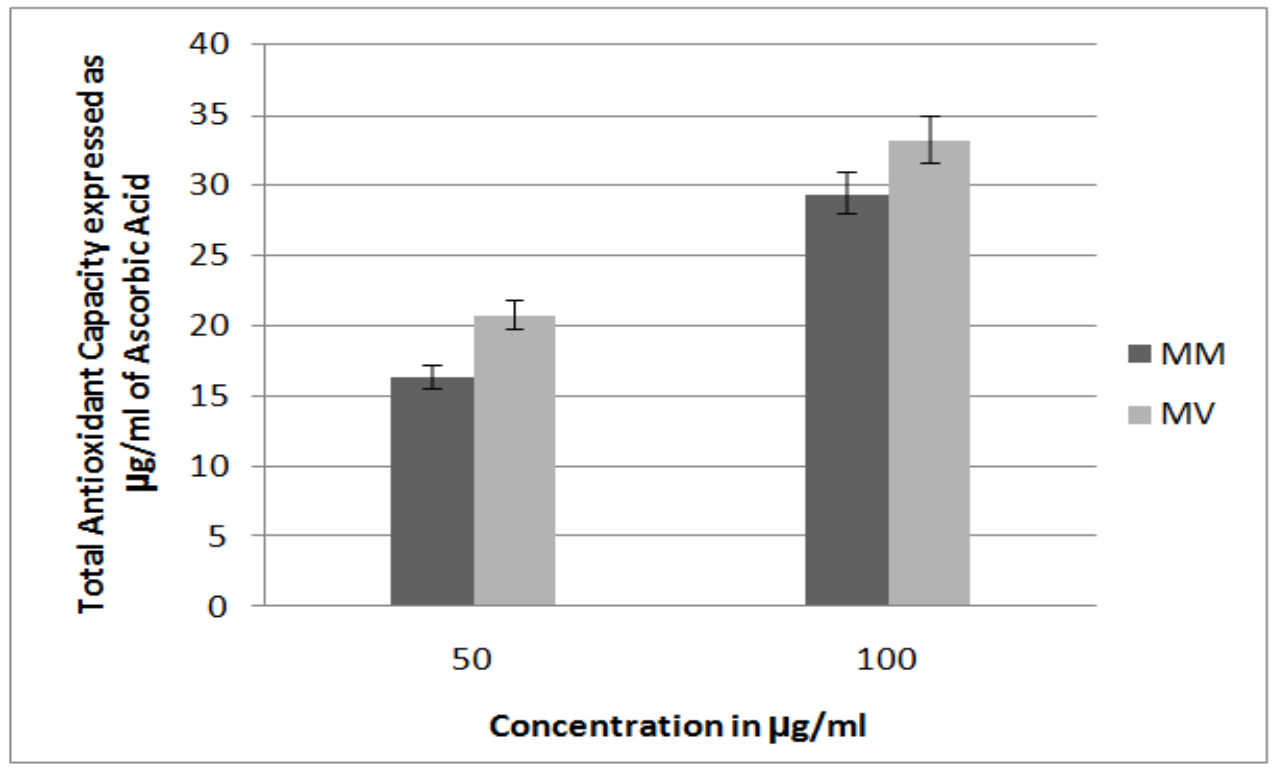


Fig.6 DPPH Radical Scavenging Activities of Extracts of Field Grown (MM) and Tissue Cultured (MV) Mentha piperita L. in Comparison with Ascorbic Acid (AA) (Values are Expressed as Mean + SEM, $n=3$ )

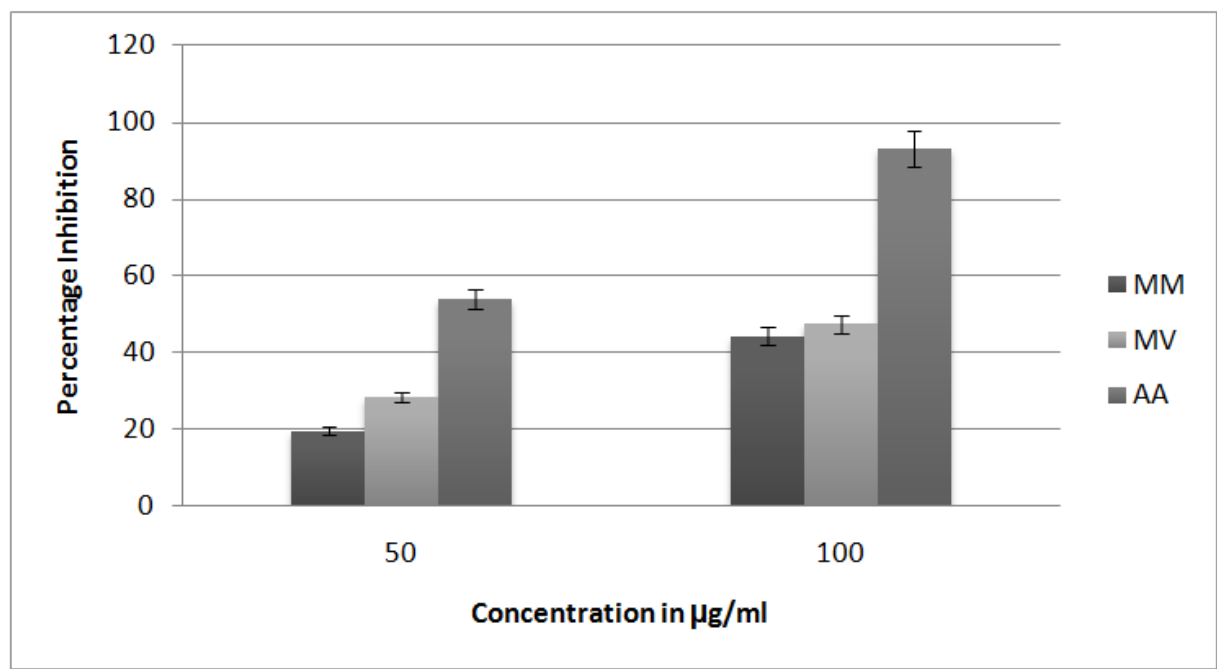

When DPPH accepts an electron donated by an antioxidant compound, the DPPH is decolorized which can be quantitatively measured from the changes in absorbance. The radical scavenging activity of the extracts was observed from the decrease in absorbance of the DPPH with the extract with increase in concentration at $512 \mathrm{~nm}$. This manifested in the rapid discoloration of the purple DPPH to light yellow suggesting the radical scavenging activity of the methanol extract of Mentha was due to its proton donating ability (Gami et al., 2011). The percentage inhibition of the field grown plant extract is $44.15 \pm 0.35$, while that of the tissue cultured plants is 47.23 2.0 .28 . Ascorbic acid the well-known antioxidant has a percentage inhibition of $92.97 \pm 0.11$.The results indicate that the in vitro cultured plants contain a high concentration of antioxidant compounds. The extract of Mentha arvensis showed highest DPPH radical scavenging activity, when compared to plants like Moringa oleifera, Trigonella foenumgraceum and other plants (Raghavendra et al., 2013). The present results suggests that the extracts are apparently good free radical scavenger and probably have the ability to inhibit auto oxidation of lipids and could thus be beneficial in the treatment of various diseases where lipid peroxidation is an important mechanism for pathogenesis (Aliyu et al., 2013).

In conclusion, the present investigation a simple and rapid in vitro propagation protocol has been established. Both the field grown and tissue culture derived plants were shown to have significant amount of polyphenolic components, expressed as gallic acid equivalents. The results of antioxidant evaluation based on two models, DPPH and TAC used in this study revealed that the methanolic extract of both field grown and tissue cultured Mentha piperita possess interesting antioxidant activity. It was observed that the antioxidative properties of the field grown plants were well maintained in the tissue culture derived plants suggesting in vitro regeneration as an alternative for sustainable use of this medicinally important threatened plant. These observations enhance potential 
interest in the culinary herbs for improving the efficacy of different products as neutraceutical and pharmacological products.

\section{Acknowledgement}

The authors are thankful for financial assistance from DBT, under the DBT Star college scheme, Department of Botany, Lady Brabourne College, Kolkata.

\section{References}

AkashDeep, Rana, P., Gosal, S., Soni, G. 2013. Antioxidant potential of tissue cultured Mentha spicata. J. Pharm. Res., 1: 90-96.

Aliyu, A., Ibrahim, M., Musa, A., Kiplimo, J., Oyewale, A. 2013. Free radical scavenging and total antioxidant capacity of root extracts of Anchomones difformis Engl. (Araceae). Acta Poloniae Pharmaceutica Drug Res., 70(1): 115-121.

Aliyu, A.B., Ibrahim, M.A., Ibrahim, H., Musa, A.M., Lawal, A.Y., Oshanimi, J.A., Usman, M., Abdulkadir, I.E., Oyewate, A.O., Amupitan, J.O. 2012. Free radical scavenging and total antioxidant capacity of methanol extract of Ethulia conyzoides growing in Nigeria. Romanian Biotechnol. Lett., 17: 7458-7465.

Dode, L.B., Bobrowski, V.L., Braga, E.J.B., Selxas, F.K., Schuch, M.W. 2003. In vitro propagation of Ocimum basilicum L. (Lamiaceae). Acta. Scientia. Biol. Sc., 25: 435.

Ebrahimzadeh, M.A., Nabavi, S.M., Nabavi, S.F. 2010. Biological activities of Mentha spicata. Pharmacol. online., 1: 841-848.

Gami, B., Kothari, I.L. 2011. Antioxidant and antimicrobial activity of in vivo and in vitro grown plants of Phyllanthus niruri L. Int. J. Pharm. Biosci., 2(2).

Ghanti, K., Kaviraj, C.P., Venugopal, R.B., Jabeen, F.T.Z., Rao, S. 2004. Rapid regeneration of Mentha piperita L. from shoot tip and nodal explants. Ind. J. Biotech., 3: 594-598.

Julia, K., Claudia, J. 2012. Draught, salt, temperature stress induced metabolic rearrangements and regulatory networks. J. Expert Bot., 63: 15931608.

Kahkonen, M.P., Hopia, A.I., Vuorela, H.J., Pihlaja, K., Kujala, T.S., Heinonen, M. 1999. Antioxidant activity of plant extracts containing phenolic compounds. J. Agri. Food Chem., 47: 3954-3962.

Lahiri, K. 2010. Micropropagation, cytomolecular and chemical analysis of different varieties and regenerated plants of Mucuna pruriens L.Ph.D. Thesis, University of Calcutta.

Le Floch, F.,Tena, M.T., Rios, A., Valcarcel, M. 1998. Supercritical fluid extraction of phenol compounds from olive leaves. Talanta, 46: 1123-1130.

Miller, H.E., Rigelhof, F., Marquart, L., Prakash, A., Kanter, M. 2000. Antioxidant content of whole grain breakfast cereals, fruits and vegetables. J. Amer. Coll. Nutri., 19(3): 312S-319S.

Murashige, T., Skoog, F. 1962. A revised medium for rapid growth and bioassays with tobacco tissue culture. Physiol. Pl., 15: $473-497$.

Phatak, S.V., Heble, M.R. 2001. Organogenesis and terpenoid synthesis in Mentha arvensis. Fitoterapia, 73: 32-39.

Prieto, P., Pineda, M., Aguilar, M. 1999. Spectrophotometric quantitation of antioxidant capacity through the formation of phosphomolybdenum 
complex: specific application to the determination of Vit E. Annal. Biochem., 269: 339-341.

Raghavendra, H., Lakshmanashetty, Vijayananda, B., Nagaraj, Madhumathi, G., Hiremath, Vadlapudi Kumar. 2010. In vitro antioxidant activity of Vitexnegundo.L.leaf extracts. Chiang Mai J. Sci., 37: 489497.

Ravn, H., Pedersen, M.F., Andray, J., Borum, C., Anthoni, U., Christophersen, C., Neilsen, P.H. 1994. Seasonal variation and distribution of two Phenolic compounds, rosmarinic acid and caffeic acid, in leaves and rootsrhizomes of eelgrass (Zostera marina L). Ophelia, 40: 51-61.

Rice Evans, C., Miller, N.J., Bolwell, P.G., Bramley, P.M., Pridham, J.B. 1995.The relative antioxidant activity of plant derived polyphenolic flavonoids. Free Radical Res., 22: 375-383.

Roy, D., Mukhopadhyay, S. 2012. Enhanced rosmarinic acid production in species of Mentha. Ind. J. Exp. Biol., 50(11): 817-25.

Shimada, K., Fujikawa, K., Yahara, K., Nakamura, T. 1992. Antioxidative properties of Xanthan on the autooxidation of soybean oil in cyclodextrin. J. Agri. Food Chem., 40: 945-948.

Siatk, T., Kasparova, M. 2010. Seasonal variation in total phenolic and flavonoid contents and DPPH scavenging activity of Bellis perennis L. flowers. Molecules, 15: 9450-9461. Sreenivasan, S., Ibrahim, D., MohdJassim, M.J.N. 2007. Free Radical scavenging activity and total phenolic compounds of Gracilaria changii. 2007. Int. J. Nat. Eng. Sci., 1: 115-117.

Sunandakumaril, C., Martin, K.P., Chithral, M., Sinil, S., Odanan, P.V.M. 2004. Rapid axillary bud proliferation and $e x$ vitro rooting of herbal spice, Mentha piperita L. Ind. J. Biotech., 3: 108112.

Tisserat, B., Vaughn, S. 2008. Growth, morphogenesis and essential oil production in Mentha spicata L. shoots in vitro. In vitro Cell Dev. Biol., 44: 40-50.

Zheng, W., Wang, S.Y. 2001. Antioxidant activity and phenolic compounds in selected herbs. J. Agri. Food Chem., 49: 5165-5170.

\section{How to cite this article:}

Bidisha Mallick, Suchita Sinha and Debleena Roy. 2016. Evaluation of Antioxidative Potential of Field Grown and Tissue Culture Derived Mentha piperita L.Plants. Int.J.Curr.Microbiol.App.Sci. 5(3): 382-391. doi: http://dx.doi.org/10.20546/ijcmas.2016.503.045 